\title{
Etnografias em contextos pedagógicos: alteridades, agências e insurgências
}

\author{
JULIANE BAZZO \\ UNIVERSIDADE FEDERAL DA GRANDE DOURADOS (UFGD), DOURADOS/MS, BRASIL \\ HTTPS://ORCID.ORG/OOOO-000I-6IO6-3482
}

EVA SCHELIGA

UNIVERSIDADE FEDERAL DO PARANÁ (UFPR), CURITIBA/PR, BRASIL

HTTP://ORCID.ORG/OOOO-0002-2270-0636

Com satisfação apresentamos aos leitores da Campos o dossiê Etnografias em contextospedagógicos. A iniciativa de organização deste dossiê remonta ao grupo de trabalho homônimo que integrou a programação da XIII Reunião de Antropologia do Mercosul (RAM), ocorrida em Porto Alegre em 2019. Juliane Bazzo foi uma das coordenadoras da atividade e Eva Scheliga participou como debatedora em uma das sessões ${ }^{1}$. Ao longo da reunião pudemos conhecer e explorar pesquisas que, em comum, reconheciam que embora a educação não se restrinja ao espaço das instituições de ensino, estas se revelam centrais nos processos de socialização no Ocidente. Tais entidades se mostram, dessa maneira, como potentes lócus para investidas etnográficas em favor da compreensão de processos sociais, estejam eles já em curso ou ainda por nascer.

A positiva recepção à proposta do GT, que contou com a participação de investigadoras(es) de diferentes centros de pesquisa, logo suscitou a expectativa de aprofundar as discussões ali iniciadas e de reunir contribuições originais e etnograficamente informadas que interpelassem os campos da An-

1 Cada qual vinha, de diferentes modos, se dedicando a esta temática. Bazzo (2018), desde a sua pesquisa de doutorado, debruçava-se sobre a problemática dos marcadores sociais da diferença, do bullying e dos eventos extremos de violência juvenil, no escopo da etnografia escolar. Tal investigação culminou na criação do blog Primavera nos dentes (disponível em: https://blogprimaveranosdentes.wordpress. $\mathrm{com} /$ ), um espaço de divulgação científica cujo conteúdo entrecruza debates antropológicos sobre a escola e a realidade brasileira. Scheliga, por sua vez, aproximou-se do tema a partir da organização do blog Antropologia e educação - o ensino e as instituiçôes escolares como objeto etnográfico (disponível em: https://antropologiaeeducacaoblog.wordpress.com/), realizado com a colaboração de Patrícia Carvalho Rosa, Virgínia Lourençon da Silva, Caroline Leonardi de Quadros e Giovanna Gabriela da Silva Vargas, com vistas a montar um repositório de referências para subsidiar atividades de pesquisa e de ensino desenvolvidas no âmbito da UFPR. 
tropologia e da Educação. O enfoque propriamente etnográfico das pesquisas - sejam as sediadas em instituições de ensino, sejam as que tangenciassem temáticas do cotidiano pedagógico e cujo pano de fundo residia nos dilemas e desafios sociopolíticos contemporâneos - nos levou a propor à Campos a recepção de um dossiê sobre o tema.

A revista tem como missão, justamente, a publicação de trabalhos que apostam no reconhecimento do valor singular da etnografia para a Antropologia, tornando-se também vitrine da pluralidade de perspectivas teóricas e temáticas envolvidas no fazer etnográfico. Em sintonia com o foco da revista, nossa expectativa era angariar artigos que explorassem a etnografia não enquanto um método - o que, de fato, ela não é -, mas sim que a situassem como uma narrativa a um só tempo empírico-teórica, fruto de pesquisa qualitativa aprofundada, do exercício radical de estranhamento, além da primazia da intersubjetividade na construção de um conhecimento capaz de descolonizar e pluralizar percepções de mundo (Peirano 2014).

Optamos por lançar chamada aberta, convidando à submissão manuscritos que elegessem como objeto privilegiado de análise as problemáticas vividas nas e pelas instituições de ensino, como também em seu entorno. Quatro eixos temáticos nos interessavam de modo especial: (i) o avanço de governamentalidades neoliberais no Ocidente e, em especial, na cena latino-americana, onde se aprofundam regimes antidemocráticos, com impactos expressivos sobre políticas e vivências educacionais (Wacquant 2012; Gallego 2018; Cássio 2019); (ii) o entrecruzamento de marcadores de alteridade, de práticas de governo e da construção de subjetividades nos universos formais de ensino (Ong 2003; Biehl et al. 2007; Mahmood 2012; Hooks 2017); (iii) a dor, o sofrimento social, bem como eventos ordinários e extraordinários de violência ali conformados (Das 2007; Asad 2011); (iv) como também afetos, agências e insurgências mobilizados pelos sujeitos que tecem vida nesses espaços (Ortner 2007; Holston 2008; Low 2017; Ingold 2018).

Para nossa satisfação, recebemos dezenas de contribuições, elaboradas por pesquisadoras(es) de todas as regiões do Brasil e também da Argentina em resposta à chamada divulgada no final de outubro de 2019 e aberta até 31 de maio de 2020. Não podemos deixar de sublinhar que parte considerável do trabalho de composição dos manuscritos e de organização deste dossiê se fez, portanto, já sob o regime remoto, imposto em meio às incertezas, anseios e contratempos decorrentes da pandemia de CoviD-19. A significativa adesão à chamada deste dossiê neste contexto pandêmico ganhou, assim, outros matizes, deixando-nos particularmente honradas pela disposição ao diálogo conosco, mesmo em tempos tão adversos.

$\mathrm{Na}$ etapa de avaliação ad hoc, contamos com a colaboração de mais de cinquenta colegas. Estão incluídos neste rol tanto investigadores independentes quanto profissionais das redes públicas estaduais e de instituições federais de educação, com atuação no Ensino Médio e/ou no Ensino Superior - em Faculdades de Educação e em Institutos de Ciências Humanas e Sociais -, todos com formação em ou forte trânsito pela Antropologia. Aproveitamos para expressar nossa gratidão aos nossos pares pelos estimulantes pareceres os quais, certamente, trouxeram contribuições efetivas tanto para as(os) autoras(es) quanto 
para nós, editoras ${ }^{2}$. Igualmente agradecemos às autoras e aos autores por terem dialogado de modo efetivo com as(os) pareceristas anônimas(os) e conosco ao longo de todos estes meses de intenso trabalho.

Como fruto deste esforço coletivo, apresentamos ao público leitor um conjunto de contribuições, distribuídas em três números consecutivos. Nossa opção por dividir o dossiê em três edições se deu tanto em virtude do volume de colaborações aprovadas quanto em razão da diversidade de temas explorados nos textos, que tão bem expressa o dinamismo e as transformações pelas quais os estudos antropológicos em educação vêm passando. Na primeira delas agrupamos os trabalhos que, em comum, tematizam a socialidade em contextos pedagógicos, com ênfase às agências infanto-juvenis e aos modos cotidianos de produzir devires.

$\mathrm{Na}$ edição 22(1) 2021 traremos um conjunto de textos que abordam o entrecruzamento de marcadores tais como raça, gênero, sexualidade e religião em relação à experiência escolar e universitária, refletindo sobre o lugar da diferença nos contextos pedagógicos analisados. $\mathrm{O}$ último número que integra este dossiê - a edição 22(2) 2021 - será composto por artigos que problematizam experiências de ensino de Antropologia, de formação de professores, bem como de educação intercultural em territórios indígenas. Trata-se, por certo, apenas de um arranjo dentre tantos outros possíveis, uma vez que as linhas que costuram o dossiê atravessam os textos e permitem ler o conjunto de múltiplas maneiras.

Compondo a capa deste primeiro número, estão as ilustrações produzidas por Caroline Leonardi de Quadros (a quem reiteramos agradecimentos) a partir de fotografias de trabalhos de campo gentilmente cedidas à revista por Kamille Brescansin Mattar, Marilín López Fittipaldi e Fernanda Müller, autoras que integram esta edição. $\mathrm{O}$ artifício de transformação dos registros fotográficos em desenhos resulta de um cuidado para não expor as(os) interlocutoras(es) em situação de menoridade legal, nem tampouco os contextos etnográficos que demandam sigilo. O recurso à ilustração também se mostra potente ao permitir a síntese de elementos que perpassam as diferentes pesquisas tematizadas nos artigos: as mobilizações estudantis; a fruição do tempo nos intervalos entre aulas; a peculiar arquitetura das instituições de ensino; a cumplicidade entre as(os) estudantes e docentes; as festas e celebrações que pontuam o calendário escolar.

Antes de passarmos à apresentação dos artigos que integram o presente número, traçamos a seguir um breve panorama acerca das investigações antropológicas em educação no Brasil, no qual resgatamos marcos de constituição, apresentamos evidências atuais de maturidade e vivacidade, assim como discutimos algumas perspectivas de desenvolvimento.

\section{Uma mirada analítica e seu amadurecimento}

O caminho para a concretização deste dossiê foi pavimentado por uma série de outros que vêm sendo organizados por antropólogas(os) brasileiras(os) com foco na interface antropologia-educação, especialmente a contar de meados da segunda década dos anos 2000 (Oliveira 2015; Maggie et al. 2015; Gusmão et al. 2016; Eckert et al. 2017a; Rosistolato 2018b; Nascimento et al. 2020; Carneiro et al. no prelo). 
$\mathrm{Na}$ literatura antropológica brasileira revelou-se recorrente a afirmativa de que, no país, esse recorte investigativo se encontrava em processo de constituir-se, em contraste com uma produção mais representativa no mesmo viés em outras nações, principalmente na América do Norte e na Europa (Brandão 2001; Gusmão 2013; Gomes, Gomes 2013). Argumentamos que esse estado da arte enseja uma revisão, posto que tal corrente de estudos tem ofertado, nos anos recentes, sinais de amadurecimento, em volume, diversidade e densidade de contribuições. Logo, há indícios concretos de avanços em direção à demanda de Silva (2001) por uma "antropologia crítica da educação" capaz de robustecer e legitimar mais amplamente esse universo de pesquisas.

De fato, tal vertente possui demarcado, originalmente, um lugar periférico na produção antropológica do Brasil. Desde a década de 1970 registrou-se um envolvimento regular de antropólogas(os) em projetos e políticas educacionais dirigidos a diferentes segmentos da população brasileira, especialmente entre os povos indígenas, mas também em universos urbanos que se expandiam e complexificavam (Tassinari 2008; Gusmão 2014; Oliveira et al. 2016).

É, todavia, a partir dos anos 1990 que uma antropologia centrada na educação tem impulso no país, diante do estabelecimento do Ensino Básico como um direito pela Constituição de 1988, com novas políticas públicas daí decorrentes $(i d .)^{3}$. Esse cenário, em plena redemocratização, partilhava uma atmosfera mais ampla, presente no continente latino-americano, que envolveu uma singular propulsão de investigações de perfil qualitativo, influenciada pela efervescência de movimentos sociais e de iniciativas de educação popular, em prol da ampliação de direitos e, nessa esfera, do fortalecimento do ensino público (Milstein 2020).

A alavancagem dos estudos antropológicos em educação no Brasil debruçou-se, não obstante, sobre temas bastante circunscritos. Tanto as(os) antropólogas(os), quanto as(os) educadoras(es) interessadas(os) em tal recorte detiveram suas preocupações, de início, nos desafios colocados pela escolarização indígena; na sistematização de conteúdos sobre a diversidade sociocultural brasileira nos currículos de formação docente, com aspirações de repercussões no processo de ensino-aprendizagem; assim como na popularidade do emprego da etnografia dentre os métodos qualitativos emergentes de pesquisa em educação (Gusmão 2014; Oliveira et al. 2016).

Desta última frente emergiu um debate digno de nota que, conforme demonstra Fonseca (1999), abrangeu o olhar crítico de antropólogas(os) dirigidos a uma profusão, a contar da década de 1990, de estudos em Educação caracterizados inapropriadamente como etnografias, devido tão somente ao seu cunho qualitativo ou, ainda, pela reflexividade das(os) autoras(es). Segundo ela, nesse quadro, etapas inerentes a uma concreta empreitada etnográfica se expunham descumpridas: o "estranhamento" no trabalho de campo; a "esquematização dos dados empíricos"; a "desconstrução dos estereótipos preconcebidos", além da "comparação" viabilizada pela consulta sistematizada ao patrimônio teórico-etnográfico já acumulado.

3 Até então, a Sociologia constituía no Brasil o braço das Ciências Sociais com produção mais significativa acerca da educação como tema. A Sociologia da Educação é, assim, um subcampo disciplinar bem estabelecido e suas investigaçôes se revelam referências para as abordagens antropológicas - vide, nesse sentido, Fernandes (2004 [1944]), além de Bourdieu e Passeron (1996 [1970]). 
Essa discussão mostrou-se a tal ponto melindrosa - nesse sentido, $c f$. também Valente (1996) que Gomes e Gomes (2013) afirmam ter deixado propositadamente de fora a "etnografia em estudos da escola e de processos educacionais" em sua revisão sobre "antropologias da educação" no Brasil, elaborada para um compêndio global acerca desse campo de estudos. De acordo com as autoras, no que tange a tal recorte específico de pesquisas evidenciava-se até aquele momento a "ausência de um diálogo teórico mais sistemático" (ibid.: 117, nossa tradução).

Dessa forma, a dupla fez um apanhado de contribuições em três linhas temáticas - relações raciais e educação; juventude, escola e educação contemporânea; além da infância e educação indígena -, nas quais as investigações apareciam construídas via observação participante, história oral, análise do discurso, estudos de caso, levantamentos quantitativos, como também sob apoio de um "approach etnográfico", o que não implicava a feitura da etnografia stricto sensu (id.).

Desde a segunda década dos anos 2000, contudo, esse panorama passa a sinalizar modificações em nosso país, mais uma vez sob estímulo de novas políticas públicas. Assinadas pelos governos petistas no poder executivo, essas iniciativas se deram nos domínios da inclusão econômica e do reconhecimento da diversidade sociocultural, com impactos expressivos ao longo do tempo no cotidiano e na formação de docentes e discentes, em diferentes níveis de ensino (Gusmão 2014; Oliveira et al. 2016)4 . De tal universo de medidas é mister enfatizar aqui a promulgação da Lei n. 11.684/2008, que tornou obrigatórias as disciplinas de Sociologia e Filosofia no currículo do Ensino Médio, fato este responsável por fazer efervescer debates, reflexões e estudos sobre processos educacionais próprios às Ciências Sociais, no trânsito entre a academia e a escola (Brum 2019)5.

Importa notar, entretanto, que na execução de várias dessas políticas vestidas de benefícios, paradoxalmente colocaram-se entre a educação, de um lado e os cidadãos, de outro, intermediários de peso, tais como as instituições bancárias e os conglomerados privados de ensino. Desse modo, embora siga a tônica neoliberal instalada no país durante o mandato de Fernando Henrique Cardoso nos anos 1990, o projeto de governo petista inseriu-se em uma "política de compromisso" inédita, focada a um só tempo nos segmentos dos "extremos da sociedade": "os muito ricos e os muito pobres" (Souza 2016).

Tratou-se, assim, de um arranjo sociologicamente injusto, que mantém iniquidades seculares, contudo, pragmaticamente vantajoso a segmentos sociais mais desfavorecidos, tamanha a precariedade determinada pelas estrondosas desigualdades presentes no Brasil. Como sabido, esse estado de coisas encontrou sustentabilidade temporária, definitivamente desfeita com o controverso impeachment da presidenta Dilma Rousseff, em meio à instauração de uma crise político-econômica de grande magnitude (id.). Perante esse turbulento cenário as investigações antropológicas em educação no Brasil não apenas vêm

4 Dentre tais intervenções aparecem a ampliação do Fundo de Financiamento Estudantil - Fies (Lei n. 10.260/2001); o ensino obrigatório de história e cultura afro-brasileira nas escolas (Lei n. 10.639/2003); o Programa Bolsa Família (Lei n. 10.836/2004); o Programa Brasil sem Homofobia (2004); o Programa Universidade para Todos - Prouni (Lei n. 11.096/2005); o ensino obrigatório de história e cultura indígena nas escolas (Lei n. 11.645/2008); a Política de Educação Especial na Perspectiva da Educação Inclusiva (2008); a Política de Valorização do Salário Mínimo (Lei n. 12.382/2011); o Programa de Acesso ao Ensino Técnico - Pronatec (Lei n. 12.513/2011) e a Lei n. 12.711/2012, que delimitou cotas socioeconômicas, étnico-raciais e de pessoas com deficiência para ingresso em instituições federais de ensino.

5 Assinala-se o engajamento da Associação Brasileira de Antropologia (ABA) em discutir, gerar conhecimento e intervir nessa temática, algo traduzido no trabalho ativo de comissões, na circulação periódica de publicações de panorama (Grossi et al. 2006; Tavares et al. 2010; Simião, Feldman-Bianco 2018), além dos grupos de trabalho e fóruns específicos abrigados em seus eventos. 
pluralizando seus temas de pesquisa nos últimos anos, como também têm se dedicado, com maior afinco, a efetuar imersões no dia a dia das instituições de ensino, fitando etnograficamente os "contextos pedagógicos" (Guedes 2014), em trabalhos prioritariamente capitaneados por antropólogas(os).

Logo, conforme aponta exame de Rosistolato (2018a:4), constata-se no tempo presente o fortalecimento da produção de estudos que estabelecem a "escola como lócus privilegiado para investigações antropológicas da educação". Isso se dá no interior de uma linha de pesquisas cuja aposta reside na feitura da etnografia educacional num sentido forte, contemplando nesse âmbito também processos de aprendizagem não formais, extramuros das instituições de ensino. Trata-se, assim, de uma vertente que não substitui, antes se distingue daquela de estudos em educação com “approach etnográfico" (Gomes, Gomes 2013), que não se veem compelidos a "cumprir [...] todos os requisitos da etnografia, especificamente a longa permanência do pesquisador em campo, o contato direto e sistemático com outras culturas e a utilização de categorias amplas para a análise dos fenômenos sociais mapeados" (Rosistolato 2018a:2).

Como fruto desse panorama, além do conjunto de dossiês em periódicos citado no início desta seção, é emblemática a coletânea organizada por Guedes e Cipiniuk (2014), intitulada Abordagens etnográficas sobre educação: adentrando os muros das escolas. Originada a partir do Seminário sobre Educação e Antropologia, promovido em 2012 pelo Programa de Pós-Graduação em Antropologia da Universidade Federal Fluminense (UFF), a obra reúne dois blocos de pesquisas etnográficas. Um primeiro tem por cenário empírico relações de socialidade em escolas de ensino público e um segundo abarca, simultaneamente, contextos da educação religiosa escolar, da educação de jovens e adultos, além daquele de expansão de matrículas no Ensino Superior no Brasil, por meio do Programa Universidade para Todos (Prouni).

$\mathrm{Na}$ mesma direção, são igualmente representativos os esforços do Núcleo de Identidades de Gênero e Subjetividades (NIGS), atuante desde 1991 no Departamento de Antropologia da Universidade Federal de Santa Catarina (UFSC), sob coordenação da professora Miriam P. Grossi. Esse coletivo lançou em 2017 duas coletâneas de artigos com investidas etnográficas a mesclar educação, gênero e sexualidade. As obras foram intituladas como Sexualidades, juventude e representaçóes docentes: uma etnografia da educação básica em escolas públicas de Santa Catarina (Grossi et al. 2017) e Antropologia, gênero e educação em Santa Catarina (Welter et al. 2017). Na apresentação desta última, por exemplo, as organizadoras afirmam que a obra teve "foco na escola como principal espaço de produção e reprodução de conhecimentos e valores. [...] A formação de estudantes e professoras/es e violências de gênero, homo-lesbo-transfobia e racismo no espaço escolar são os [...] grandes eixos temáticos do livro" (ibid.:10).

Em um provocativo artigo, no clima dessas transformações, Pereira (2017) conclama pelo fortalecimento definitivo de uma antropologia em educação enquanto universo investigativo cuja atuação, além de considerar seus tópicos originais de pesquisa, transcenda-os, para acessar com rigor etnográfico o "chão da escola", ou seja, a "concretude das relações vividas" nesse espaço e tudo aquilo que o impacta. Nesse movimento seria possível contemplar não só as escolas, mas também os estabelecimentos de Ensino Superior que, a exemplo daqueles em educação básica, têm gerado pesquisas no escopo em tela. 
Assim, a despeito das bem-vindas críticas que têm sido feitas ao modelo hegemônico de ensino formal, dentre elas a reprodução de desigualdades, Ingold (2018) destaca que seria errôneo almejar "uma sociedade sem escolas", porque, no complexo mundo da atualidade, não há como abrir mão delas. Hoje, revela-se impossível que "tudo o que alguém precisa saber seja aprendido através da participação na vida de uma comunidade" circunscrita (ibid.:16, nossa tradução). Dessa maneira, o desafio ainda residiria em promover transformações mais robustas no formato de educação formal ainda vigente, na direção de contemplar a diversidade e de efetivar a justiça social.

\section{Entre conectivos e possibilidades}

A interface entre duas áreas do saber com especificidades bem próprias - a Antropologia, cujo projeto seminal é o conhecimento da alteridade e a Educação, que tem o propósito primeiro de uma intervenção pedagógica sobre a realidade (Gusmão 2014; Guedes 2014) - ao mesmo tempo em que propiciou avanços investigativos, também definiu controvérsias. Uma delas, já mencionada, envolveu a problematização das especificidades da etnografia como um modo, dentre outros, de gerar e difundir saberes na corrente de pesquisas em foco aqui. Outro ponto de especial discussão entre as(os) estudiosas(os) cristalizou-se nas dissidências sobre como nomear essa vertente de investigações.

De um lado, há as(os) que preferem chamá-la de 'antropologia da educação'. Essa escolha, principalmente abraçada por antropólogas(os) lotadas(os) em departamentos acadêmicos de Antropologia, dá proeminência à contribuição dos pressupostos dessa ciência para a prática educacional. De outro lado, situam-se aquelas(es) que entendem mais adequada a denominação 'antropologia $e$ educação', uma terminologia que seria, para esse grupo, mais paritária e dialógica entre os dois universos do saber (Eckert et al. 2017b). Essa segunda nomenclatura não só surge defendida por pesquisadoras(es) do campo da Educação, mas também por antropólogas(os) que se inserem em espaços universitários de ensino dessa área do conhecimento. Ou seja, vê-se em jogo nessa divergência vocabular não só visões epistemológicas, mas também questões de inserção institucional (nesse sentido, $c f$. Dauster 2014).

Nos idos recentes, com a chamada "virada ontológica” (Sztutman 2013) que decorre na Antropologia e em outras Ciências Humanas, no Brasil e no mundo, emergiram indagações de nova natureza sobre os laços não pacificados entre os dois campos em questão. Taddei e Gamboggi (2016) falam em uma "educação da antropologia", propondo pela "reversão dos termos" a dissolução de uma histórica relação assimétrica entre as duas frentes de saberes. Nessa interface, a Antropologia, desde o Norte global, teria sido constantemente "evocada para esclarecer o que é a educação, ou pelo menos o que são suas práticas institucionalizadas, como a escola, e quais implicações elas têm para a vida coletiva" (ibid.: 29). O contrário, entretanto, não se mostraria recorrente. Ademais, esses autores pontuam que a Antropologia ainda se encontra em débito quanto a um debate teórico-metodológico mais extenso acerca da "educação dos antropólogos" e também sobre os “antropólogos como educadores”, para além, portanto, de descrições pontuais já realizadas de "genealogias intelectuais".

Ingold (2018), pensador também afinado à referida "virada", advoga por uma "antropologia como educação". Sem pretensão de vínculo ao já demarcado campo da antropologia da educação, o autor 
defende que essas duas instâncias do saber, mais que capazes de estabelecerem relações, possuem uma "congruência fundamental", posto serem pautadas pelos mesmos "princípios". Baseado nos escritos filosóficos de John Dewey, Ingold (id.) traça paralelismos entre uma educação "contra-hegemônica”, não sinônima à mera "transmissão do conhecimento autorizado" e uma antropologia decidida a liquefazer suas dicotomias clássicas de análise, que ecoam contextos coloniais de conquista, nos quais a disciplina se constituiu. Em síntese, para ele, tanto uma ciência quanto a outra devem ser "práticas de atenção", dedicadas a desvelar "as condiçôes e possibilidades de ser humano", a dialogar "sobre a própria vida humana" e a assegurar a "continuidade da vida".

Cientes dos prementes desafios de revisão que tal debate coloca a uma linguagem dominante no Ocidente - bem abordados quanto à sua dificuldade no caso da escrita antropológica por Strathern (2006 [1988]), por exemplo - problematizamos mais uma possibilidade terminológica, alinhada ao teor de parte considerável das contribuições que conformam o presente dossiê. Em verdade, voltamo-nos à “antropologia da educação", nomenclatura que desencadeia as críticas supracitadas, para lançar a ela um olhar mais nuançado. Tal proposta não se guia, logo, por com quê a ciência antropológica poderia contribuir, de modo unidirecional, para a prática educativa.

Consideramos essa mirada pautada, sim, por um deslizamento de problemáticas de investigação, semelhante àquele que Simões (2018) indica ter ocorrido de uma "antropologia política" a uma "antropologia da política” no Brasil. Neste último caso, a política - assim como a educação, para nossos propósitos aqui - emerge "[...] como categoria etnográfica, [discernida] em uma variedade de eventos, situações e relações sociais. Nesse sentido, é menos uma área temática do que um modo de pesquisa e análise que atravessa diferentes temas" (ibid.: 75-76).

Sob essa luz e conforme se verifica nos artigos deste dossiê, se a etnografia em contextos pedagógicos formais ganha impulso no Brasil em idos recentes, trata-se de uma antropologia da educação que se dá no mesmo compasso em que pesquisadoras(es) problematizam a escolarização também para além de suas fronteiras imediatas. Em outras palavras, vê-se um rol de estudos a contemplar uma trama social complexa de agentes, filosofias, políticas, técnicas e performances, cujas alianças, tensões, ações e interligações não raro se fazem fora, porém, com rebatimentos significativos intramuros das entidades educacionais, as quais os manejam e os devolvem, a seu modo, à sociedade. E é justamente nos meandros desses entrelaçamentos contingentes que se vê emergir um expressivo potencial investigativo (Bartlett, Triana 2020).

\section{Os artigos do número}

$\mathrm{Na}$ presente edição apresentamos sete trabalhos. $\mathrm{O}$ artigo que abre o dossiê, assinado por Bóris Maia (2020), traz à baila a etnografia de uma manifestação estudantil ocorrida em uma escola pública do Estado do Rio de Janeiro, na atmosfera da "Primavera Secundarista”, movimento fruto das “Jornadas de Junho de 2013" e que envolveu uma série de insurreições contra o sucateamento da educação brasileira. Tais levantes discentes receberam atenção de estudos antropológicos, resgatados por Maia em seu 
artigo. $\mathrm{O}$ autor, entretanto, confere ênfase a um aspecto que não surge em vitrine nessas investigações, mais detidas em pensar como as mobilizações estudantis emergiram e se desenvolveram.

Maia lança especial luz a como se desenrolaram os processos de desmobilização do alunado que, no caso objeto de sua análise, resultaram na nomeação de uma diretoria escolar interventora pelas autoridades estatais, em uma medida antidemocrática, inusitadamente apoiada por alunas e alunos. A partir desse acontecido desconcertante o autor problematiza o que constituiria a "escola decente" para tais estudantes, em contraste com a visão de outros agentes a esse respeito, incluindo os acadêmicos.

Reflexões sobre a socialidade política no âmbito das escolas reaparecem no segundo trabalho, de Marilín López Fittipaldi (2020). Ela debruça-se, por sua vez, sobre a matriz conceitual que orienta o funcionamento cotidiano dos chamados bachilleratos populares na Argentina, escolas de nível secundário para jovens e adultos em situação de vulnerabilidade social, cujos estudos não foram concluídos em periodização considerada regular pelo Estado. Tais estabelecimentos possuem respaldo do poder público, porém são administrados por organizações da sociedade civil, orientadas pelo princípio da "gestão social".

Por meio de uma etnografia de longa duração em uma dessas escolas na cidade de Rosário, a autora revela como esse conceito-chave é agenciado no dia a dia, em discursos e práticas, pelas pessoas que ali convivem. A ideia institucionalizada de "gestão social" logo ganha ares singulares ao ser manejada ora por docentes, ora por discentes, exercendo influência em tensões, negociações e alianças dentro de cada um dos dois grupos e também entre eles. A partir disso, López Fittipaldi evidencia uma dimensão política não episódica, manifestada no cerne da escola e que encontra na agência estudantil um de seus eixos estruturantes.

Já Kamille Brescansin Mattar e Maria Tarcisa Silva Bega (2020) apresentam uma investigação baseada em observação participante, cujo cenário empírico é uma escola estadual situada em uma periferia da cidade de Curitiba (PR). Ao tomar um conjunto de jovens estudantes dessa instituição enquanto sujeitos de pesquisa, as autoras refletem sobre em que medida as experiências escolares deles surgem moldadas pelas condições socioterritoriais da região em que se situa o estabelecimento de ensino e onde muitos também residem.

Sob essa perspectiva, Mattar e Bega constatam uma ambivalência fundante a mobilizar o vínculo que tais discentes constroem com a escola, que pendula entre o estigma de localidade e o afeto frutificado da socialidade cotidiana. A análise por elas tecida é exitosa em demonstrar que a experiência estudantil de cada jovem se dá profundamente contextualizada, recheada por um simbolismo peculiar, algo que os sistemas educacionais precisam considerar se quiserem, de fato, promover uma escola que faça sentido à vida daqueles que a habitam.

O tema da socialidade nas escolas que perpassa os textos anteriores é revisitado sob novo prisma no trabalho de María Mercedes Hirsh (2020). Tendo como pano de fundo as "perguntas sobre o futuro", a pesquisadora acompanha um grupo de estudantes secundaristas de Cañuelas, Argentina, em suas atividades na escola e para além dela, em seu último ano acadêmico. Parte de sua pesquisa é dedicada à observação das políticas de acompanhamento dos jovens em suas escolhas por cursos universitários e a consequente apreciação que fazem do Ensino Superior, como uma espécie de passaporte 
para uma melhor condição de vida e superação de dificuldades. Em seguida, Hirsh nos brinda com dados sobre a agência dos estudantes na criação coletiva de "projetos de futuro", o que também pode ser antevisto por meio do profundo envolvimento dos jovens com os rituais de formatura que pontuam o calendário escolar.

De ponta a ponta no artigo o que está sob análise é o complexo jogo de "individualização e de moralização", nas palavras da autora, que envolve a enunciação e a elaboração de respostas às indagações sobre o devir em um contexto marcado por relações de grande desigualdade social. A pesquisa de Hirsh põe desta forma em evidência o quanto as inquietações gerais sobre o futuro de indivíduos e de grupos sociais incidem fortemente sobre os modos como as instituições escolares são produzidas e reguladas, tornando as escolas espaços estratégicos para se observar como são engendrados os "projetos de vida" ${ }^{\prime 6}$. Esta reflexão de algum modo também acompanha os textos seguintes, neles ganhando outros contornos.

Mario Pereira Borba (2020) dedica seu artigo à abordagem de um tema clássico nos estudos educacionais de países em desenvolvimento: o fracasso escolar, incorporado na figura do "repetente". Faz isso por intermédio da etnografia de um projeto de adaptação idade-série ou de aceleração do segundo ciclo do Ensino Fundamental, experiência que tomou forma em uma escola pública da cidade do Rio de Janeiro.

As interlocuções travadas em campo pelo autor revestem-se do mérito de revelar que defrontar o fenômeno da multirrepetência demanda lidar com muito mais que uma certa técnica em tese capaz de tornar um programa de aceleração eficiente. Diz respeito, sim, a encarar uma série de representações sociais sobre atrasos, hesitações e persistências no processo de escolarização, subjetivadas em meio a estudantes e docentes. Tais "projeções", demonstra Borba, dão conta da existência de distintas categorias de repetentes, que engendram, por sua vez, diferentes trajetórias de malogro. Esse cenário matizado, desvelado pelo projeto em foco, acaba por interpelar a escola acerca de dilemas constituintes à educação moderno-ocidental, para muito além da questão da repetência tomada isoladamente.

O texto de Fernanda Müller (2020), por sua vez, nos leva a outro contexto educativo: o que cerca a transição de uma bebê para a creche. A autora toma uma experiência próxima como objeto de uma rica discussão sobre a socialização - outro tema clássico dos estudos de Sociologia e de Antropologia, por ela revisitado à luz de uma bibliografia contemporânea. Como fio condutor de seu artigo, elege os múltiplos sentidos que a tradicional canção do "Parabéns pra você" assumiu no processo de produção de sujeitos que ela acompanhou em seu experimento de pesquisa.

Ao explorar as pistas em torno dos rituais preparatórios para o ingresso da bebê em uma creche, Müller não só colabora para a consolidação dos estudos etnográficos sobre infância, como também enfrenta outro importante desafio: o de elaborar e traduzir, em dados objetivos, uma intensa experiên-

6 Não pode nos escapar aqui o comentário de que tal expressão recentemente foi incorporada ao vocabulário técnico-pedagógico brasileiro por ocasião da implantação da Base Nacional Comum Curricular (BNCC) do Ensino Médio. "Projeto de vida" passou a designar um componente curricular presente nos três anos do Ensino Médio. Também não nos escapa o possível papel de agências internacionais, tais como a Unesco, na difusão de determinado programa que apoia o "protagonismo juvenil", mas que lhe confere sentido específico em termos de impulso ao empreendedorismo, desenvolvimento da inteligência emocional e engajamento a favor de uma "cultura da paz". Esta tríade dá sustentação aos projetos, individuais e coletivos, incentivados em múltiplos contextos pedagógicos e que, não por acaso, ressoam tanto no Brasil como na Argentina. 
cia intersubjetiva, haja vista que a criança protagonista do artigo é sua sobrinha. A autora tampouco deixa escapar à reflexão alguns dos efeitos das dinâmicas impostas pelo isolamento social em virtude da pandemia de CoviD-19 - o que, sem dúvida, é uma contribuição oportuna também ao debate sobre como dar continuidade às pesquisas etnográficas em tempos tão adversos como este que vivenciamos durante a crise sanitária.

Assim como Müller, Bernardo Fonseca Machado (2020) também desloca o eixo de nossa atenção para um contexto pedagógico diverso, o teatral. Sua pesquisa foi desenvolvida em duas escolas voltadas à formação de atores e atrizes de teatro musical, uma localizada em São Paulo, outra em Nova York. Neste artigo, as aulas das disciplinas de audição desenvolvidas nestes espaços de formação são o ponto de partida para sua reflexão sobre a constituição do chamado perfil, dispositivo através do qual a produção de diferenças é engendrada, disputada e inscrita nos corpos das(os) aspirantes à carreira neste segmento artístico.

A comparação entre os dois contextos, tecida com particular acuidade, nos ajuda a compreender os meandros da inculcação das diferenças que, pouco a pouco, constroem "princesas" e "vilóes", personagens envolvendo uma densa pedagogia dos corpos. Machado explora, desta forma, um campo pouco frequentado, porém extremamente fértil para as reflexões sobre os processos de aprendizado, indissociáveis da naturalização de convenções e da atualização de estruturas moralizantes de raça, gênero e sexualidade. Seu texto antecipa, assim, alguns dos pontos abordados no próximo número do dossiê.

Esperamos que este primeiro conjunto de textos possa contribuir para com o vigoroso e multifacetado campo de estudos antropológicos em educação, expandindo o rol de referências que dão suporte às pesquisas e, sobretudo, oferecendo aportes etnográficos para o adensamento das reflexões sobre os contextos pedagógicos, seus agentes e dinâmicas.

Desejamos a todas(os) uma boa leitura!

Juliane Bazzo é Doutora em Antropologia Social pela Universidade Federal do Rio Grande do Sul(UFRGS) e Professora Visitante no Programa de Pós-Graduação em Antropologia da Universidade Federal da Grande Dourados (UFGD).

Eva Scheliga é Doutora em Ciência Social (Antropologia Social) pela Universidade de São Paulo (USP) e Professora Adjunta da Universidade Federal do Paraná (UFPR).

\section{REFERÊNCIAS BIBLIOGRÁFICAS}

Asad, Talal. 2011. “Thinking about the Secular Body, Pain and Liberal Politics”. Cultural Anthropology 26(4): 657-675. doi: https://doi.org/10.1111/j.1548-1360.2011.01118.x 
Bartlett, Lesley e Claudia Triana. 2020. "Antropologia da Educação: introdução”. Educação \& Realidade 45(2): 1-6. doi: http://dx.doi.org/10.1590/2175-623699887

Bazzo, Juliane. 2018. Agora tudo é bullying': uma mirada antropológica sobre a agência de uma categoria de acusação no cotidiano brasileiro. Tese de doutorado. Porto Alegre: Universidade Federal do Rio Grande do Sul. Disponível em: https://lume.ufrgs.br/handle/10183/174498

Biehl, João, Byron Good e Arthur Kleinman (ed). 2007. Subjectivity: ethnographic investigations. Berkeley, Los Angeles, London: University of California Press.

Borba, Mario P. 2020. "Projeções de atrasos e hesitações: perspectivas em torno de um projeto de aceleração em uma escola pública do Rio de Janeiro". Campos - Revista de Antropologia 21(2): 122-141.

Bourdieu, Pierre e Jean-Claude Passeron. 1996 [1970]. La reproducción: elementos para una teoría del sistema de enseñanza. Coyoacán: Fontamara.

Brandão, Carlos Rodrigues. 2001. “Sobre teias e tramas de aprender e ensinar: anotações a respeito de uma antropologia da educação". Inter-Ação 26(1):8-47. doi: https://doi.org/10.5216/ia.v26i1.1552

Brum, Ceres K. 2019. “Os 10 anos da Sociologia no ensino médio no Brasil: considerações sobre a formação de professores de Ciências Sociais na UFSM”. Politica \& Sociedade 18(41):187-214. doi: http://dx.doi.org/10.5007/2175-7984.2019v18n41p187

Carneiro, Jeannie, Ana Moura e Aleksandra Oliveira (ed). no prelo. "Educar a quem, educar a quê?" Dossiê. Equatorial. Disponível em: https://periodicos.ufrn.br/equatorial

Cássio, Fernando (ed). 2019. Educação contra a barbárie: por escolas democráticas e pela liberdade de ensinar. São Paulo: Boitempo.

Das, Veena. 2007. Life and words: violence and the descent into the ordinary. Berkeley, Los Angeles: University of California Press.

Dauster, Tania. 2014. "O universo da escola e dos profissionais da área da educação: tensões e proximidades entre a antropologia e a educação". Pp. 25-36 in Abordagens etnográficas sobre educação: adentrando os muros das escolas, ed. S. L. Guedes \& T. A. Cipiniuk. Niterói: Alternativa.

Eckert, Cornélia, Neusa Gusmão, Sandra Tosta e Tania Dauster (ed).2017a. "Antropologia, Etnografia e Educação”. Dossiê. Horizontes Antropológicos 23(49):9-407. doi: https://doi.org/10.1590/ s0104-71832017000300001

Eckert, Cornélia, Neusa Gusmão, Sandra Tosta e Tania Dauster. 2017b. “Apresentação”. Dossiê Antropologia, Etnografia e Educação. Horizontes Antropológicos 23(49):9-18. doi: https://doi. org/10.1590/s0104-71832017000300001 
Fernandes, Florestan. 2004 [1944]. "As 'trocinhas' do Bom Retiro”. Pro-posições 15(1): 229-250. Disponível em: https://periodicos.sbu.unicamp.br/ojs/index.php/proposic/article/view/8643855

Fonseca, Claudia. 1999. “Quando cada caso não é um caso: pesquisa etnográfica em educação”. Revista Brasileira de Educação 10:58-78.

Gallego, Esther S. (ed). 2018. O ódio como politica: a reinvenção das direitas no Brasil. São Paulo: Boitempo.

Gomes, Ana Maria e Nilma L. Gomes. 2013. "Anthropology and education in Brazil: possible pathways". Pp. 111-129 in Anthropologies of education: a global guide to ethnographic studies of learning and schooling, ed. K. M. Anderson-Levitt. New York, Oxford: Berghahn Books.

Grossi, Miriam P., Antonella P. Tassinari e Carmen Rial (ed). 2006. Ensino de Antropologia no Brasil: formação, práticas disciplinares e além fronteiras. Blumenau: Nova Letra.

Grossi, Miriam P., Felipe Fernandes e Fernanda Cardozo (ed). 2017. Sexualidades, juventude e representaçôes docentes: uma etnografia da educação básica em escolas públicas de Santa Catarina. Florianópolis, Tubarão: Tribo da Ilha, Copiart.

Guedes, Simoni L. 2014. “Por uma abordagem etnográfica dos contextos pedagógicos”. Pp. 7-10 in Abordagens etnográficas sobre educação: adentrando os muros das escolas, ed. S. L. Guedes \& T. A. Cipiniuk. Niterói: Alternativa.

Guedes, Simoni L. e Tatiana Cipiniuk (ed). 2014. Abordagens etnográficas sobre educação: adentrando os muros das escolas. Niterói: Alternativa.

Gusmão, Neusa. 2013. “Antropologia e/da Educação no Brasil”. Entrevista a Amurabi Oliveira. Cadernos de Campo 22:147-160. doi: https://doi.org/10.11606/issn.2316-9133.v22i22p147-160

Gusmão, Neusa M. M. de. 2014. “Trajetória, percalços e conquistas da antropologia da educação no Brasil”. Pp. 13-24 in Abordagens etnográficas sobre educação: adentrando os muros das escolas, ed. S. L. Guedes \& T. A. Cipiniuk. Niterói: Alternativa.

Gusmão, Neusa, Marion Teodósio e Gunter Dietz (ed). 2016. “Antropologia, Educação, Alteridades e Desigualdades”. Dossiê. Revista Anthropológicas 27(1):1-244. Disponível em: https://periodicos. ufpe.br/revistas/revistaanthropologicas/article/view/24033

Hirsh, María Mercedes. 2020. “De las preguntas por el futuro a los proyectos individuales: un abordaje etnográfico sobre los proyectos de futuro de los jóvenes en la finalización de la escuela secundaria”. Campos - Revista de Antropologia 21(2): 99-121. 
Holston, James. 2013. Cidadania insurgente: disjunçôes da democracia e da modernidade no Brasil. São Paulo: Companhia das Letras.

Hooks, bell. 2017. Ensinando a transgredir: a educação como prática da liberdade. 2 ed. São Paulo: WMF Martins Fontes.

Ingold, Tim. 2018. Anthropology and/as education. London, New York: Routledge.

López Fittipaldi, Marilín. 2020. "Hacer escuela, hacer colectivo. Movimientos sociales, jóvenes y experiencias educativas desde una perspectiva antropológica (Rosario, Argentina)". Campos - Revista de Antropologia 21(2): 50-74.

Low, Setha. 2017. "Emotion, affect and space". Pp. 145-173 in Spatializing culture: the ethnography of space and place. London, New York: Routledge.

Machado, Bernardo F. 2020. “Os usos do 'perfil' - formas de ensino e práticas da diferença em escolas de teatro musical". Campos - Revista de Antropologia 21(2): 143-167.

Maggie, Yvonne, Helena Sampaio e Ana Pires do Prado (ed). 2015. "Anthropology and Education". Dossier. Vibrant 12(2):71-496. doi: https://doi.org/10.1590/1809-43412015v12n2p071

Mahmood, Saba. 2012. "Pedagogies of Persuasion". Pp. 79-117 in Politics of Piety: the Islamical revival and the feminist subject. Princeton: Princeton University Press, 2012.

Maia, Bóris. 2020. "Do protesto à intervenção: socialização política, cidadania e insurgência em mobilizações estudantis em escolas públicas". Campos - Revista de Antropologia 21(2): 28-49.

Mattar, Kamille B. e Maria Tarcisa S. Bega. 2020. "Entre estigmas e afetos: a experiência escolar de jovens em uma periferia de Curitiba-PR". Campos - Revista de Antropologia 21(2): 75-98.

Milstein, Diana. 2020. “Children, youths and ethnography: education and de-centering”. Diálogos sobre Educación 20:1-10. doi: https://doi.org/10.32870/dse.v0i20.694

Müller, Fernanda. 2020. “Parabéns pra você’: reflexões na quarentena sobre a transição de uma bebê para a creche". Campos - Revista de Antropologia 21(2): 142-163.

Nascimento, Raimundo Nonato do, Marion T. Quadros e Vânia Fialho (ed). 2020. "Antropologia, Educação e Diversidade”. Dossiê. Revista Entrerios 3(1):5-108. Disponível em: https://revistas.ufpi. br/index.php/entrerios/article/view/11636

Oliveira, Amurabi (ed). 2015. “Antropologia e Educação”. Dossiê. Linhas Criticas 21(44):11-177. doi: https://doi.org/10.26512/lc.v21i44.4461 
Oliveira, Amurabi, Beatriz Búrigo e Felipe Boin. 2016. "A antropologia, os antropólogos e a educação no Brasil”. Anthropológicas 27(1):21-44. Disponível em: https://periodicos.ufpe.br/revistas/revistaanthropologicas/article/view/24035

Ong, Aihwa. 2003. Buddha is hiding: refugees, citizenship, the new America. Berkeley: University of California Press.

Ortner, Sherry B. 2007. "Poder e projetos: reflexões sobre a agência”. Pp. 45-80 in Conferências e diálogos: saberes e práticas antropológicas, ed. M. P. Grossi, C. Eckert e P. Fry. Blumenau: Nova Letra.

Peirano, Mariza. 2014. “Etnografia não é método”. Horizontes Antropológicos 20(42):377-391. doi: http://dx.doi.org/10.1590/s0104-71832014000200015

Pereira, Alexandre B. 2017. "Do controverso 'chão da escola' às controvérsias da etnografia: aproximações entre antropologia e educação". Horizontes Antropológicos 23(49):149-176. doi: https://doi. org/10.1590/s0104-71832017000300006

Rosistolato, Rodrigo. 2018a. "A liberdade dos etnógrafos em educação e seu mosaico interpretativo". Revista Contemporânea de Educação 13(26):1-9. doi: http://dx.doi.org/10.20500/rce.v13i26.17153

Rosistolato, Rodrigo (ed). 2018b. "Estudos etnográficos em Educação”. Dossiê. Revista Contemporânea de Educação 13(26):1-243. doi: http://dx.doi.org/10.20500/rce.v13i26.17153

Silva, Araci L. 2001. "Uma 'antropologia da educação' no Brasil? Reflexões a partir da escolarização indígena”. Pp. 29-43 in Antropologia, História e Educação: a questão indígena e a escola, ed. A. L. Silva e M. K. L. Ferreira. 2. ed. São Paulo: Global.

Simião, Daniel S. e Bela Feldman-Bianco (ed). 2018. O campo da Antropologia no Brasil: retrospectiva, alcances e desafios. Rio de Janeiro: Associação Brasileira de Antropologia.

Simões, Júlio A. 2018. "A dinâmica do campo: temas, tendências e desafios". Pp 57-82 in O campo da Antropologia no Brasil: retrospectiva, alcances e desafios, ed. D. S. Simião e B. Feldman-Bianco. Rio de Janeiro: Associação Brasileira de Antropologia.

Souza, Jessé. 2016. A radiografia do golpe: entenda como e por que vocêfoi enganado. Rio de Janeiro: LeYa.

Strathern, Marilyn. 2006 [1988]. O gênero da dádiva: problemas com as mulheres e problemas com a sociedade na Melanésia. Campinas: Editora da Unicamp.

Sztutman, Renato. 2013. "Posfácio: as ideias em jogo". Pp. 137-152 in Fora de contexto: as fiç̧ôes persuasivas da Antropologia, M. Strathern. São Paulo: Terceiro Nome. 
Taddei, Renzo e Ana Laura Gamboggi. 2016. “Educação, antropologia, ontologias”. Educação e Pesquisa 42(1):27-38. doi: https://doi.org/10.1590/s1517-9702201506134264

Tassinari, Antonella M. I. 2008. "A educação escolar indígena no contexto da Antropologia brasileira”. Ilha 10(1):217-244. doi: https://doi.org/10.5007/2175-8034.2008v10n1p217

Tavares, Fátima, Simoni L. Guedes e Carlos Caroso (ed). 2010. Experiências de ensino e prática em Antropologia no Brasil. Brasília: Ícone Gráfica e Editora.

Valente, Ana Lúcia E. F. 1996. “Usos e abusos da antropologia na pesquisa educacional”. Pro-Posições 7(2):54-64. Disponível em: https://periodicos.sbu.unicamp.br/ojs/index.php/proposic/article/ view/8644228

Wacquant, Loïc. 2012. "Três etapas para uma antropologia histórica do neoliberalismo realmente existente". Caderno CRH 25(66): 505-518. doi: http://dx.doi.org/10.1590/S010349792012000300008

Welter, Tânia, Miriam P. Grossi e Mareli Graupe. (ed). 2017. Antropologia, gênero e educação em Santa Catarina. Tubarão, Florianópolis: Copiart, Mulheres. 


\title{
ETNOGRAFIAS EM CONTEXTOS PEDAgógicos: ALTERIDADES, AgÊNCIAS E INSURGÊNCIAS
}

Resumo: Embora a educação não se restrinja ao espaço das instituições de ensino, estas se revelam centrais nos processos de socialização no Ocidente. Com esse mote em vista, empreendemos neste texto três movimentos analíticos. Situamos o processo de composição do dossiê Etnografias em contextos pedagógicos, destacando as respostas ao convite para tomar variados espaços de educação formal como centro de pesquisas que mobilizam a etnografia em seu sentido forte. Em seguida, traçamos o percurso de consolidação e diversificação dos estudos antropológicos em educação no Brasil, lançando também olhares sobre as possibilidades abertas pelas etnografias em contextos pedagógicos. Por fim, destacamos algumas chaves de leitura do material apresentado neste primeiro número do dossiê desdobrado em três edições, alinhavadas pelas discussões sobre alteridades, agências e insurgências manifestadas nos universos escolares da contemporaneidade.

Palavras-chave: Antropologia da educação; etnografia escolar; contextos pedagógicos; agências; alteridades.

\section{ETHNOGRAPHIES IN PEDAgOGICAL CONTEXTS: ALTERITIES, AGENCIES AND INSURGENCIES}

\begin{abstract}
Although education not restricted itself to the space of educational institutions, they are central to the socialization processes in the West. With this motto in mind, we have undertaken three analytical movements in this text. We situate the process of composing the dossier called Ethnographies in pedagogical contexts, highlighting the responses to the invitation to take various spaces of formal education as a researches center that mobilize ethnography in its strong sense. Then, we trace the consolidation and diversification path of anthropological studies in education in Brazil, also looking at the possibilities opened by ethnographies in pedagogical contexts. Finally, we highlight some keys for reading the material presented in this first issue of the dossier divided into three editions, based on discussions about alterities, agencies and insurgencies manifested in contemporary school universes.
\end{abstract}

Keywords: Anthropology of education; school ethnography; pedagogical contexts; agencies; otherness.

RECEBIDO EM: 26/02/2021

APROVADO EM: 23/03/2021 